\title{
UM ESTUDO PRELIMINAR SOBRE AS DEFINIÇÕES E AS DIFERENÇAS DOS PRINCIPAIS TIPOS DE ARRANJOS EMPRESARIAIS
}

\section{A PRELIMINARY STUDY ON THE DEFINITIONS AND DIFFERENCES OF MAIN TYPES OF BUSINESS ARRANGEMENTS}

\author{
Anderson Tiago Peixoto Gonçalves* E-mail: adm.andersontiago@gmail.com \\ Maria Silene Alexandre Leite* E-mail: leite@ct.ufpb.br \\ Ricardo Moreira da Silva* E-mail: ricardomoreira0203@hotmail.com \\ *Universidade Federal da Paraíba - UFPB
}

\begin{abstract}
Resumo: Com o crescimento da competitividade e das exigências do mercado, diversas empresas têm se organizado conjuntamente com o intuito de formar parcerias, constituindo os chamados Arranjos Empresariais, a fim de que sejam alcançadas vantagens competitivas. Este artigo partiu da necessidade de analisar as definições e as diferenças dos principais tipos de Arranjos Empresariais existentes, visto que na literatura têm sido utilizadas diversas nomenclaturas e classificações, seja em função da forma como o Arranjo é gerido; o modo como está organizado; a conformidade com que os membros exercem suas atividades; a forma como ocorre o fluxo de recursos e informações; o grau de articulação e interação; a forma de organização da produção; e as estratégias adotadas. Trata-se de uma pesquisa básica, descritiva e bibliográfica, a qual buscou coletar nas fontes pertinentes, definições acerca de cada Arranjo, para cumprir o objetivo do artigo que é estudar as definições e as diferenças dos principais tipos de Arranjos Empresariais. Justifica-se o artigo pela escassez de definições uniformizadas na literatura que tornem possível a visualização das diferenças existentes entre cada um dos tipos de Arranjos, principalmente daqueles nos quais as definições mais se assemelham.
\end{abstract}

Palavras-chave: Arranjos Empresariais. Definições. Diferenças.

Abstract: With the growth of competitiveness and market requirements, several companies have been jointly organized with the aim of forming partnerships, forming the so-called Business Arrangements, to ensure that competitive advantages are achieved. This article came from the need to review the definitions and differences between the main types of existing Business Arrangements, as in the literature have been used different nomenclatures and classifications, either in terms of how the Arrangement is managed, how it is organized, the according to which members carry out their activities, how is the flow of resources and information, the degree of coordination and interaction, the form of production organization, and the strategies adopted. It is a basic research, descriptive and literature, which sought to collect the relevant sources, definitions about each Arrangement to meet the goal of the article is to study the definitions and differences between the main types of Business Arrangements. The article is justified by the scarcity of uniform definitions in the literature that make it possible to visualize the differences between each of the types of Arrangements, especially those in which the definitions are more similar.

Key-words: Business Arrangements. Definitions. Differences. 


\section{ASPECTOS INTRODUTÓRIOS}

A concorrência cada vez mais acirrada, em virtude de um ambiente mutável e competitivo, de flutuações no mercado e de inovações tecnológicas, tem levado as empresas a buscarem novas idéias, ferramentas e métodos a fim de aperfeiçoarem sua gestão e a melhorar continuamente seu desempenho produtivo (BARROS, 2010). Assim, as empresas têm criado elos de cooperação entre elas na intenção de promover espaços de maiores oportunidades de investimento e aquisição de tecnologias. $E$ as formas com que essas empresas têm se organizado conduzem ao fortalecimento mútuo para sobreviver e competir (ALBUQUERQUE, 2001).

No ambiente organizacional, segundo Human e Provan (1997) e Mozzato (2010), tem-se percebido a importância de serem pensadas novas formas de relacionamentos interorganizacionais, através de relações de cooperação como alternativas estratégicas viáveis e competitivas.

Cabe neste momento diferenciar cooperação e colaboração. Aquele está geralmente ligado às ações inversas à competição no sentido de trabalho complementar, porém com o objetivo de resultados para ambos os parceiros. $\mathrm{Na}$ colaboração, observa-se diferença sutil na finalidade da ação, que não prevê benefícios para ambos, nem se enquadra num sentido de reciprocidade. A colaboração está mais situada no contexto de apoio, gerando benefício para um dos parceiros (WINCKLER; MOLINARI, 2011).

Neste contexto, Brito e Leite (2008) afirmam que diversas empresas tem se organizado conjuntamente para formar os chamados Arranjos Empresariais, que têm como um dos seus objetivos criar ou consolidar vantagens competitivas entre membros que os compõem, através do compartilhamento da sua gestão.

Para Lastres e Cassiolato (2005), a formação de Arranjos encontra-se geralmente associada a trajetórias históricas de construção de identidades e de formação de vínculos territoriais locais, a partir de uma base social, cultural, política e econômica comum.

$\mathrm{Na}$ literatura, vários têm sido os termos criados para identificação dos Arranjos Empresariais, porém, pelo fato destes termos muitas vezes serem usados como se fossem sinônimos, tem havido um desentendimento com relação ao verdadeiro significado de cada um deles (CABETE; DACOL, 2008). No Brasil, o termo que é mais utilizado, inclusive pelo Governo Federal, é o de Arranjo Produtivo Revista Produção Online, Florianópolis, SC, v.12, n. 3, p. 827-854, jul./set. 2012. 
Local ou simplesmente APL. Porém, a utilização do termo não está isenta de controvérsias, já que diferentes termos e diferentes conceitos são utilizados para expressar este mesmo fenômeno (SUZIGAN, 2006).

Há várias lógicas que exploram as definições, características e aplicações conceituais dos tipos de Arranjos e, freqüentemente, dificultam o entendimento de aspectos que possam distinguir de maneira clara um Arranjo de outro. Logo, distinguir esses relacionamentos entre organizações não é tarefa fácil, uma vez que determinadas características podem ser comuns a alguns tipos de Arranjos, entretanto, a visualização de diferenças estruturais parece ser distintiva em alguns formatos (LEITE; BRITO; OLIVEIRA, 2009).

Em cada caso há características distintas em termos de história, evolução, organização institucional, contextos sociais e culturais, da forma de organização da produção, e da forma de governança local. Nesse sentido, é possível encontrar diferenças significativas entre muitas das diversas experiências no que se refere a graus de desenvolvimento, de articulação e interação entre agentes e instituições locais, e de capacidades sistêmicas para a inovação (SUZIGAN, 2006).

Alguns dos principais termos relacionados aos Arranjos Empresariais encontrados e discutidos na literatura, segundo os estudos realizados por Brito e Leite (2008); Leite, Brito e Oliveira (2009), são: Arranjo Produtivo Local (APL), Clusters, Redes de Empresas, Cooperativas, Cadeia Produtiva ou Filière, Cadeia de Suprimentos ou Supply Chain, Condomínio Industrial e Consórcio Modular.

Independentemente da forma que o Arranjo assuma, para Crocco et al. (2003), estas formas de organização tem auxiliado empresas dos mais variados tamanhos e, particularmente, as pequenas e médias empresas, a superarem barreiras ao seu crescimento. De um lado, a proximidade física das empresas propiciaria o surgimento de externalidades, pecuniárias e tecnológicas. De outro, a proximidade física e cognitiva cria condições para uma interação cooperativa. Além de que ideias são trocadas e desenvolvidas, e o conhecimento é compartilhado numa tentativa coletiva de melhorar a qualidade de produtos e processos; de ocupar segmentos de mercado; de coordenar ações e resolver problemas conjuntamente.

Para Jorde e Teece (1989), os Arranjos possibilitam o aumento do acesso a novos conhecimentos, facilita a aprendizagem organizacional, o acesso às novas tecnologias, e o processo de inovação. 
Um ponto comum observado nas experiências dos Arranjos Empresariais, que molda uma de suas características essenciais, é a capacidade de geração de economias externas, as quais têm papel fundamental para o incremento da competitividade (SUZIGAN, 2006). O conceito de economias externas refere-se àqueles benefícios que as firmas obtêm do fato de estar operando em uma situação de aglomeração setorial e/ou territorial (KELLER, 2008).

Suzigan (2006) explica que além das economias externas incidentais, os agentes econômicos podem reforçar sua capacidade competitiva por meio de ações conjuntas deliberadas, tais como compra de matéria prima, promoção de cursos de capacitação gerencial e formação profissional, contratação de serviços especializados, estabelecimento de centros tecnológicos de uso coletivo, cooperativas de crédito, entre outros.

Segundo Schmitz e Nadvi (1999), a junção das economias externas incidentais com as alcançadas por ações conjuntas deliberadas, resulta na chamada eficiência coletiva, principal determinante das capacidades competitivas das empresas. Os autores apontam a primeira como sendo a eficiência coletiva passiva, a qual diz respeito às condições coletivas que são dadas naturalmente, não exigindo nenhum esforço dos agentes econômicos; e a segunda como eficiência coletiva ativa, que requer um posicionamento ativo por meio de ações conjuntas, requerendo esforços dos diferentes agentes econômicos.

Quanto às diferenças, Mori, Batalha e Alves Filho (2009) dizem que os tipos de Arranjos se diferenciam na forma como ocorre o fluxo de recursos e informações, na intensidade das trocas intra e inter-aglomeração, nas relações de cooperação, no grau de especialização e desintegração vertical da aglomeração e na capacidade inovativa. Complementando os autores supracitados, Lastres e Cassiolato (2005) apontam características que os definem, tais como: dimensão territorial; diversidade de atividades e atores econômicos, políticos e sociais; conhecimento tácito, inovação e aprendizado interativos, governança e grau de enraizamento.

A partir das afirmações dos autores pode-se dizer que a identificação da tipologia de um determinado Arranjo Empresarial necessita da análise de algumas de suas particularidades tais como: a forma como é gerido; o modo como está organizado; a conformidade com que os componentes exercem suas atividades; a forma como ocorre o fluxo de recursos e informações; o grau de articulação e 
interação entre os membros; a forma de organização da produção; e as estratégias adotadas para obter vantagens competitivas.

Para que se possa desenvolver novos instrumentos de gestão aplicáveis aos Arranjos Empresariais, é condição necessária conhecer suas particularidades, dado que um Arranjo devidamente caracterizado e diferenciado poderá ser gerenciado e tratado adequadamente de acordo com o seu perfil (LEITE; BRITO; OLIVEIRA, 2009). Nesse sentido, este artigo tem por objetivo estudar, preliminarmente, as definições e as diferenças dos principais Arranjos Empresariais, devido à escassez de definições uniformizadas na literatura, que tornem possível diferenciar cada tipo de Arranjo, principalmente aqueles em que as definições mais se assemelham.

\section{ARRANJOS EMPRESARIAIS}

Nesta seção serão apresentadas as definições dos principais tipos de Arranjos Empresariais, de acordo com a classificação proposta por Brito e Leite (2008); Leite, Brito e Oliveira (2009):

\subsection{Arranjo Produtivo Local (APL)}

No Quadro 1 foram listadas seis (06) definições para APL, com a intenção de buscar pontos comuns, bem como a clareza na determinação deste tipo de Arranjo. 
Quadro 1 - Definições para Arranjo Produtivo Local (APL)

\begin{tabular}{|c|c|}
\hline Autoria & Definições \\
\hline $\begin{array}{l}\text { Maluf } \\
(2005)\end{array}$ & $\begin{array}{l}\text { São aglomerações territoriais de agentes econômicos, políticos e sociais, } \\
\text { com foco em um conjunto específico de atividades econômicas e que } \\
\text { apresentam vínculos expressivos de interação, cooperação e } \\
\text { aprendizagem voltados para o enraizamento da capacitação inovativa, } \\
\text { essencial para a competitividade empresarial e para a capacitação social. } \\
\text { Geralmente, envolvem a participação e a interação de empresas, que } \\
\text { podem ser desde produtoras de bens e serviços finais até fornecedoras de } \\
\text { insumos, prestadoras de consultoria e serviços, clientes, entre outros. } \\
\text { Incluem, também, instituições voltadas para formação e capacitação de Rh, } \\
\text { como escolas técnicas e universidades; promoção e financiamento. }\end{array}$ \\
\hline $\begin{array}{l}\text { Vasconcelos } \\
\text { et al. (2005) }\end{array}$ & $\begin{array}{l}\text { São concentrações espaciais e setoriais de empresas, instituições e } \\
\text { governos em torno de um eixo produtivo comum. }\end{array}$ \\
\hline $\begin{array}{c}\text { Suzigan } \\
(2006)\end{array}$ & $\begin{array}{l}\text { Consiste em um sistema de agentes econômicos, políticos e sociais } \\
\text { ligados a um mesmo setor ou atividade econômica, que possuem vínculos } \\
\text { produtivos e institucionais entre si, de modo a proporcionar aos produtores } \\
\text { um conjunto de benefícios relacionados com a aglomeração das empresas. } \\
\text { Configura-se um sistema complexo em que operam diversos subsistemas } \\
\text { de produção, logística e distribuição, comercialização, desenvolvimento } \\
\text { tecnológico e onde os fatores econômicos, sociais e institucionais estão } \\
\text { fortemente entrelaçados. }\end{array}$ \\
\hline $\begin{array}{c}\text { Teixeira e } \\
\text { Nascimento } \\
\text { Filho } \\
(2007)\end{array}$ & $\begin{array}{l}\text { Trata-se de um tipo específico de Cluster, composto por pequenas e } \\
\text { médias empresas, agrupadas em torno de um negócio, onde se destaca o } \\
\text { papel desempenhado pelos relacionamentos entre empresas e demais } \\
\text { instituições envolvidas. As unidades produtoras compartilham uma cultura } \\
\text { comum e interagem, como um grupo, com o ambiente sociocultural local. } \\
\text { Os APL's têm como objetivo promover competitividade e sustentabilidade } \\
\text { dos Micros e Pequenos negócios; o dinamismo econômico da região; a } \\
\text { capacidade de resposta aos desafios de exportação; desenvolvimento local } \\
\text { com geração de emprego e renda; profissionais mais qualificados e } \\
\text { diminuição das disparidades intra e inter-regionais. }\end{array}$ \\
\hline $\begin{array}{c}\text { Galdámez, } \\
\text { Carpinetti e } \\
\text { Gerolamo } \\
(2009)\end{array}$ & $\begin{array}{l}\text { São sistemas utilizados para promover a cooperação, a inovação contínua } \\
\text { e o desenvolvimento sustentável das Pequenas e Médias Empresas. O seu } \\
\text { processo de gestão de desempenho construído a partir do planejamento } \\
\text { estratégico e com a implantação de ações coletivas de melhoria contínua, } \\
\text { como também é necessário construir uma infra-estrutura local e um } \\
\text { ambiente que estimule a confiança e a cooperação dos membros. }\end{array}$ \\
\hline $\begin{array}{l}\text { Britto e } \\
\text { Stallivieri } \\
(2010)\end{array}$ & $\begin{array}{l}\text { Constitui-se em uma aglomeração espacial de agentes econômicos, } \\
\text { políticos e sociais envolvidos com um conjunto específico de atividades } \\
\text { produtivas, na qual se estruturam vínculos e relações de interdependência. } \\
\text { Por meio desses vínculos, origina-se um processo de aprendizagem que } \\
\text { possibilita a introdução de inovações de produtos, processos e formatos } \\
\text { organizacionais, gerando maior competitividade para as empresas } \\
\text { integradas ao arranjo. }\end{array}$ \\
\hline
\end{tabular}

Fonte: Maluf (2005); Vasconcelos et al. (2005); Suzigan (2006); Teixeira e Nascimento Filho (2007); Galdámez, Carpinetti e Gerolamo (2009); Britto e Stallivieri (2010) 
Analisando as definições apresentadas no Quadro 1, pode-se sugerir a partir de Maluf (2005); Vasconcelos et al. (2005); Suzigan (2006); Teixeira e Nascimento Filho (2007); Galdámez, Carpinetti e Gerolamo (2009); Britto e Stallivieri (2010) a seguinte definição para Arranjo Produtivo Local (APL): são aglomerações ou concentrações territoriais e setoriais de agentes econômicos, políticos e sociais em torno de uma atividade econômica específica, nas quais se estruturam vínculos e relações de interação, interdependência, cooperação e aprendizagem, voltadas para o enraizamento da capacitação inovativa contínua, essencial para geração de competitividade e sustentabilidade dos seus membros, como também para a promoção do dinamismo econômico local da região em que o APL está inserido, diminuindo as disparidades intra e inter-regionais.

Teixeira e Nascimento Filho (2007) ressaltam que o Arranjo Produtivo Local trata-se de um tipo específico de Cluster, composto por pequenas e médias empresas, o que leva ao entendimento de que os Clusters seriam compostos por empresas de maior porte e mais desenvolvidas. De encontro com os autores supracitados Galdámez, Carpinetti e Gerolamo (2009) também o definem como sistemas utilizáveis em busca do desenvolvimento de pequenas e médias empresas.

\subsection{Clusters}

No Quadro 2 apresentam-se sete (07) definições para Clusters, com 0 objetivo de buscar compatibilidade entre elas.

A questão da existência de outros atores no Arranjo, além das organizações com características similares, apresenta-se como um ponto contrastante entre algumas definições apresentadas, enquanto Cortright (2006) ressalta a presença de agentes econômicos relacionados e instituições, Lastres e Cassiolato (2005) acreditam na não obrigatoriedade da existência de outros atores no Arranjo. No entanto, assim como na definição de APL, há a presença de outros atores, visto que em um Cluster, não há apenas um sistema de valor que inclui fornecedores, concorrentes, clientes e empresas associadas da indústria, mas também um apoio de sistema de valores que inclui universidades, instituições financeiras e organizações intermediárias de ciência e tecnologia (JIA; LIU; XIE, 2010). 
Quadro 2 - Definições para Clusters

\begin{tabular}{|c|l|}
\hline Autoria & \multicolumn{1}{c|}{ Definições } \\
\hline (2005) & Um Cluster possui as seguintes características: rede social (não exige \\
& acordo formais), simetria (não possui um coordenador), horizontalização \\
& (os membros produzem bens similares, eles cooperam e competem entre \\
& si), estabilidade (as relações entre as empresas são estáveis), liberdade (as \\
funções não são rigorosamente definidas), intangibilidade (ocorre a \\
transferência de conhecimento entre as organizações).
\end{tabular}

Fonte: Guerrini (2005); Lastres e Cassiolato (2005); Cortright (2006); Chiaroni e Chiesa (2006); Cavalcante (2006); Galeti (2007); Jia, Liu e Xie (2010)

Logo, com base nos autores Guerrini (2005); Lastres e Cassiolato (2005); Cortright (2006); Chiaroni e Chiesa (2006); Cavalcante (2006); Galeti (2007); Jia, Liu e Xie (2010), pode-se construir a seguinte definição de Cluster: é uma aglomeração geograficamente concentrada de organizações com características similares, que trabalham direta ou indiretamente para o mesmo mercado final, com relações verticais e horizontais, mostrando uma clara tendência de cooperação e de 
compartilhamento de competências, valores e conhecimentos entre os seus membros, com ênfase na concorrência como fator de dinamismo.

\subsection{Redes de Empresas}

No Quadro 3 são apresentadas sete (07) definições para Redes de Empresas, também chamadas de Redes Interorganizacionais ou Interempresariais.

Quadro 3 - Definições para Redes de Empresas

\begin{tabular}{|c|c|}
\hline Autoria & Definições \\
\hline $\begin{array}{l}\text { Lastres e } \\
\text { Cassiolato } \\
(2005)\end{array}$ & $\begin{array}{l}\text { Refere-se a formatos organizacionais, definidos a partir de um conjunto de } \\
\text { articulações entre empresas, envolvendo a realização de transações e/ou o } \\
\text { intercâmbio de informações e conhecimentos entre os atores, não } \\
\text { implicando necessariamente na proximidade espacial de seus integrantes. }\end{array}$ \\
\hline $\begin{array}{c}\text { Amato Neto } \\
(2005)\end{array}$ & $\begin{array}{l}\text { Constituem-se, portanto, em uma alternativa quanto à forma de organizar a } \\
\text { produção de bens e serviços e podem ser utilizadas pelas empresas na } \\
\text { busca de melhoria de sua posição competitiva. }\end{array}$ \\
\hline $\begin{array}{l}\text { Nakano } \\
(2005)\end{array}$ & $\begin{array}{l}\text { Formas de organização da atividade econômica através de ações de } \\
\text { coordenação e cooperação entre empresas, baseadas ou não em contratos } \\
\text { formais, que sob o ponto de vista econômico se situam entre empresas } \\
\text { (hierarquias) e os mercados. Ou seja, as Redes Interempresariais se } \\
\text { inserem no mercado como um modelo de gestão estratégica que visa dotar } \\
\text { as estruturas organizacionais de maior capacidade competitiva para lidar } \\
\text { com a complexidade do atual ambiente de negócios. }\end{array}$ \\
\hline $\begin{array}{l}\text { Barbosa, } \\
\text { Sacomano } \\
\text { e Porto } \\
\text { (2007) }\end{array}$ & $\begin{array}{l}\text { As Redes podem ser definidas como complexas estruturas compostas por } \\
\text { empresas que, conscientemente, admitem possuir limitações estruturais, } \\
\text { financeiras e competitivas que restringem as condições de sobrevivência e } \\
\text { desenvolvimento. São baseadas em uma estrutura que contempla } \\
\text { atividades agregadoras de valor para os consumidores finais, resultando } \\
\text { em maior poder de competição para as empresas inter-relacionadas. }\end{array}$ \\
\hline $\begin{array}{l}\text { Oliveira e } \\
\text { Cândido } \\
\text { (2009) }\end{array}$ & $\begin{array}{l}\text { Em seu conceito, a empresa não é analisada isoladamente, mas sim dentro } \\
\text { de um contexto que envolve uma ou mais empresas atuando de forma } \\
\text { interativa, integrada, podendo compartilhar recursos, pessoas, tecnologias, } \\
\text { com uma única forma de atuação e uma mesma estratégia. }\end{array}$ \\
\hline $\begin{array}{l}\text { Ring, } \\
\text { Peredo e } \\
\text { Chrisman } \\
(2010)\end{array}$ & $\begin{array}{l}\text { São definidas como acordos mutuamente benéficos, com contratos } \\
\text { relacionais entre duas ou mais empresas, juridicamente independentes, que } \\
\text { envolvem o compartilhamento ou troca de recursos. }\end{array}$ \\
\hline $\begin{array}{l}\text { Vernadat } \\
\text { (2010) }\end{array}$ & $\begin{array}{l}\text { Refere-se a qualquer tipo de estrutura em que duas ou mais en } \\
\text { empresariais, geograficamente dispersas, trabalham em interação. }\end{array}$ \\
\hline
\end{tabular}

Fonte: Lastres e Cassiolato (2005); Amato Neto (2005); Nakano (2005); Barbosa, Sacomano e Porto (2007); Oliveira e Cândido (2009); Ring, Peredo e Chrisman (2010); Vernadat (2010)

Diante da complementaridade entre as definições de Lastres e Cassiolato (2005); Amato Neto (2005); Nakano (2005); Barbosa, Sacomano e Porto (2007); Oliveira e Cândido (2009); Ring, Peredo e Chrisman (2010); Vernadat (2010) para 
Rede de Empresas sugere-se a seguinte definição geral: são formatos organizacionais, definidos a partir de um conjunto de articulações entre entidades empresariais independentes e geograficamente dispersas, que atuam através de ações de coordenação, interação e cooperação, baseadas ou não em contratos formais, compartilhando recursos, pessoas, tecnologias, informações, conhecimentos, sob uma única forma de atuação e uma mesma estratégia, com o objetivo de obter maior capacidade competitiva para lidar com a complexidade do atual ambiente de negócios.

\subsection{Cooperativas}

$\mathrm{Na}$ seqüência, no Quadro 4, são apresentadas seis (06) definições para Cooperativas, as quais servirão para identificar suas principais características.

Quadro 4 - Definições para Cooperativas

\begin{tabular}{|c|c|}
\hline Autoria & Definições \\
\hline $\begin{array}{l}\text { Barreiros e } \\
\text { Protil } \\
(2005)\end{array}$ & $\begin{array}{l}\text { Constituem-se em sociedades de pessoas de poder igualitário, que se } \\
\text { unem em uma organização, visando à satisfação de necessidades comuns. } \\
\text { As cooperativas apresentam peculiaridades em sua constituição legal, com } \\
\text { a adoção de princípios e doutrinas que exercem significativos reflexos na } \\
\text { sua estruturação e governança organizacionais, delegação e exercício de } \\
\text { poder e conseqüentemente na forma como ocorre o processo decisório. }\end{array}$ \\
\hline $\begin{array}{l}\text { Machado } \\
\text { et al. } \\
\text { (2006) }\end{array}$ & $\begin{array}{l}\text { As cooperativas são organizações em que os cooperados estabelecem } \\
\text { entre si uma divisão democrática, de ajuda mútua e com objetivos } \\
\text { econômicos e sociais comuns e pré-estabelecidos. }\end{array}$ \\
\hline $\begin{array}{l}\text { Brunner e } \\
\text { Voigt } \\
\text { (2007) }\end{array}$ & $\begin{array}{l}\text { Nas cooperativas, dois aspectos do processo de decisão são enfatizados: o } \\
\text { aspecto da criação e transferência de conhecimento e a implementação de } \\
\text { medidas. Ambos os processos ocorrem tanto dentro da cooperativa como } \\
\text { também em cada empresa individualmente. Portanto, o escopo das } \\
\text { decisões empresariais não é mais limitado a uma única empresa, mas em } \\
\text { todas as empresas da cooperativa. }\end{array}$ \\
\hline $\begin{array}{l}\text { Feng e } \\
\text { Hendrikse } \\
(2007)\end{array}$ & $\begin{array}{l}\text { E uma organização em que os seus membros concordam entre si para criar } \\
\text { uma empresa e operá-la em conjunto como parte integrante de suas } \\
\text { empresas individuais. }\end{array}$ \\
\hline $\begin{array}{l}\text { Abreu et al. } \\
(2008)\end{array}$ & $\begin{array}{l}\text { Empresa formada e dirigida por uma associação de usuários, que se } \\
\text { reúnem em igualdade de direitos, com o objetivo de desenvolver uma } \\
\text { atividade econômica ou prestar serviços comuns, eliminando os } \\
\text { intermediários. }\end{array}$ \\
\hline $\begin{array}{l}\text { Novkovic } \\
\text { (2008) }\end{array}$ & $\begin{array}{l}\text { São organizações democráticas, a serviço dos seus membros, conhecidas } \\
\text { por conter uma componente social, alicerçada nos princípios de cooperação } \\
\text { e valores. }\end{array}$ \\
\hline
\end{tabular}

Fonte: Barreiros e Protil (2005); Machado et al. (2006); Brunner e Voigt (2007); Feng e Hendrikse (2007); Abreu et al. (2008); Novkovic (2008) 
A partir das definições de Barreiros e Protil (2005); Machado et al. (2006); Brunner e Voigt (2007); Feng e Hendrikse (2007); Abreu et al. (2008); Novkovic (2008) pode-se assumir a seguinte definição geral para Cooperativa: consiste em uma organização de pessoas que se reúnem voluntariamente, em igualdade de direitos, com o objetivo comum de desenvolver uma atividade econômica ou prestar serviços, a partir da criação de uma empresa de propriedade coletiva gerida democraticamente, como parte integrante das empresas individuais de cada membro. Apresentam particularidades em sua constituição legal, com a adoção de princípios e doutrinas com reflexos na sua estruturação, delegação e exercício de poder, e conseqüentemente na forma como ocorre o processo decisório.

\subsection{Cadeia de Suprimentos ou Supply Chain}

No Quadro 5 são apresentadas oito (08) definições para Cadeia de Suprimentos.

Entre as definições não são notadas discrepâncias significativas. A agregação de valor aos produtos e/ou serviços mostra-se como uma característica importante neste tipo de Arranjo, sendo enfatizado por Faria e Costa (2005); Christopher (2007); Thakkar, Kanda e Deshmukh (2008); e Barros e Alencar (2009); e Wang et al. (2009).

Logo, pode-se convergir para a seguinte definição: Cadeia de suprimentos ou Supply chain consiste em uma rede de organizações que mantêm relações mútuas, agregando valor aos produtos e/ou serviços, desde os fornecedores de matériaprima, passando pelos distribuidores, até os consumidores finais, incluindo também, eventualmente, os movimentos de retorno de produtos não consumidos ou descartados. Consiste em uma seqüência de processos e fluxos que acontecem dentro e entre estágios da cadeia, num formato contínuo e sistêmico, no qual o princípio básico está voltado à integração de informações entre seus membros. 
Quadro 5 - Definições para Cadeia de Suprimentos

\begin{tabular}{|c|c|}
\hline Autoria & Definições \\
\hline $\begin{array}{l}\text { Faria e } \\
\text { Costa } \\
(2005)\end{array}$ & $\begin{array}{l}\text { Conjunto de organizações que mantêm relações mútuas do início ao final } \\
\text { da cadeia logística, criando valor aos produtos e serviços, desde os } \\
\text { fornecedores até o cliente final. }\end{array}$ \\
\hline $\begin{array}{l}\text { Ballou } \\
(2006)\end{array}$ & $\begin{array}{l}\text { Seu princípio básico é integrar informações entre fornecedores, indústria, } \\
\text { distribuidores, varejo, atacadistas e consumidores finais, de forma a } \\
\text { ordenar, racionalizar e otimizar a produção e o escoamento dos produtos. }\end{array}$ \\
\hline $\begin{array}{l}\text { Christopher } \\
(2007)\end{array}$ & $\begin{array}{l}\text { Cadeia de suprimentos é uma rede de organizações envolvidas, por meio } \\
\text { de vínculos a montante e a jusante, nos diferentes processos e atividades } \\
\text { que produzem valor na forma de produtos e serviços destinados ao } \\
\text { consumidor final. }\end{array}$ \\
\hline $\begin{array}{l}\text { Thakkar, } \\
\text { Kanda e } \\
\text { Deshmukh } \\
\text { (2008) }\end{array}$ & $\begin{array}{l}\text { Grupo de atividades de negócio que inclui a compra em mercados, } \\
\text { manufatura ou processamento de sub-componentes/subconjuntos dentro } \\
\text { da planta e entrega às grandes empresas empregando o transporte para } \\
\text { agregar valor ao produto final e assegurar em longo prazo pedidos } \\
\text { regulares de compra. }\end{array}$ \\
\hline $\begin{array}{l}\text { Menezes, } \\
\text { Guimarães } \\
\text { e Sellitto } \\
\text { (2008) }\end{array}$ & $\begin{array}{l}\text { Uma cadeia de suprimentos ou Supply Chain é um conjunto de atividades e } \\
\text { de empresas que as desempenhem, transformando matérias-primas em } \\
\text { produtos acabados e serviços demandados por clientes finais. É uma } \\
\text { seqüência de processos e fluxos que acontecem dentro e entre estágios da } \\
\text { cadeia, agindo juntos no atendimento de pedidos de clientes. A cadeia de } \\
\text { suprimentos opera em fases físicas e em ciclos de informação: começa } \\
\text { com o consumidor; passa pelos fornecedores e pela manufatura; e volta ao } \\
\text { consumidor. Eventualmente, o retorno de itens não consumidos ou } \\
\text { descartados fecha o ciclo, em uma operação de logística reversa. O seu } \\
\text { formato faz pensar no negócio como um todo contínuo e sistêmico. }\end{array}$ \\
\hline $\begin{array}{l}\text { Barros e } \\
\text { Alencar } \\
(2009)\end{array}$ & $\begin{array}{l}\text { A cadeia de suprimentos é constituída por todas as empresas que agregam } \\
\text { valor a um determinado produto, desde a obtenção da matéria-prima até o } \\
\text { consumidor final. }\end{array}$ \\
\hline $\begin{array}{l}\text { Wang et al. } \\
\text { (2009) }\end{array}$ & $\begin{array}{l}\text { E uma rede de organizações que trabalham juntas a fim de produzir valor } \\
\text { para o cliente. Empresas em uma cadeia de suprimentos são mais } \\
\text { dependentes do acesso aos recursos de outras empresas. }\end{array}$ \\
\hline $\begin{array}{l}\text { Mo, } \\
\text { Harrison e } \\
\text { Barton } \\
(2011)\end{array}$ & $\begin{array}{l}\text { A cadeia de suprimentos centra-se na execução da tomada de decisão e } \\
\text { coordenação de abastecimento, operações e logística e fornece o principal } \\
\text { meio pelo qual as organizações produzem e entregam os seus produtos e } \\
\text { serviços aos clientes. }\end{array}$ \\
\hline
\end{tabular}

Fonte: Faria e Costa (2005); Ballou (2006); Christopher (2007); Menezes, Guimarães e Sellitto (2008); Thakkar, Kanda e Deshmukh (2008); Barros e Alencar (2009); Wang et al. (2009); Mo, Harrison e Barton (2011)

\subsection{Cadeia Produtiva ou Filière}

Oito (08) definições para Cadeia Produtiva são expostas no Quadro 6. 
Quadro 6 - Definições para Cadeia Produtiva

\begin{tabular}{|c|c|}
\hline Autoria & Definições \\
\hline $\begin{array}{c}\text { Lastres e } \\
\text { Cassiolato } \\
(2005)\end{array}$ & $\begin{array}{l}\text { Refere-se a um conjunto de etapas consecutivas pelas quais passam e vão } \\
\text { sendo transformados e transferidos os diversos insumos em ciclos de } \\
\text { produção, distribuição e comercialização de bens e serviços. Cada membro é } \\
\text { responsável pela realização de diferentes etapas do processo e podem estar } \\
\text { localizados em regiões ou localidades distintas. }\end{array}$ \\
\hline $\begin{array}{l}\text { Souza e } \\
\text { Pereira } \\
(2006)\end{array}$ & $\begin{array}{l}\text { Refere-se a um conjunto de operações técnicas responsáveis pela } \\
\text { transformação da matéria-prima em produto acabado seguido da distribuição } \\
\text { e comercialização em uma sucessão linear de operações. Expressa, } \\
\text { também, um conjunto de ações econômicas que busca acrescer valor em } \\
\text { cada etapa garantida pela articulação das operações realizadas. }\end{array}$ \\
\hline $\begin{array}{l}\text { Batalha } \\
\text { (2007) }\end{array}$ & $\begin{array}{l}\text { Filière consiste em uma sucessão de operações de transformações } \\
\text { dissociáveis, capazes de serem separadas e ligadas entre si por um } \\
\text { encadeamento técnico e também um conjunto de relações comerciais e } \\
\text { financeiras que estabelecem entre os estados de transformação um fluxo de } \\
\text { troca situado de montante à jusante, entre fornecedores e clientes. }\end{array}$ \\
\hline $\begin{array}{l}\text { Severino e } \\
\text { Eid (2007) }\end{array}$ & $\begin{array}{l}\text { Uma sucessão de operações de transformação dissociáveis, capazes de ser } \\
\text { separadas e ligadas entre si por um encadeamento técnico. Como também, } \\
\text { um conjunto de relações comerciais e financeiras que estabelecem, entre } \\
\text { todos os estados de transformação, um fluxo de troca, situado de montante à } \\
\text { jusante, entre fornecedores e clientes, e ainda um conjunto de ações } \\
\text { econômicas que presidem a valorização dos meios de produção e } \\
\text { asseguram a articulação das operações. }\end{array}$ \\
\hline $\begin{array}{l}\text { Infante e } \\
\text { Santos } \\
(2007)\end{array}$ & $\begin{array}{l}\text { Abrange desde o desenvolvimento de um produto, passando pelo fornecedor } \\
\text { de insumos, até a efetiva oferta do produto ao mercado consumidor. }\end{array}$ \\
\hline $\begin{array}{l}\text { Osório } \\
(2007)\end{array}$ & $\begin{array}{l}\text { Conjunto de atividades que envolvem desde produção de matéria-prima até } \\
\text { produto final. De acordo com a análise de "Filière", Cadeia Produtiva } \\
\text { constitui-se num termo que abrange desde o conjunto de atividades } \\
\text { articuladas para a obtenção de matéria-prima até a comercialização dos } \\
\text { respectivos produtos nos diferentes mercados. }\end{array}$ \\
\hline $\begin{array}{l}\text { Rech } \\
(2008)\end{array}$ & $\begin{array}{l}\text { A Cadeia Produtiva caracteriza-se pela coordenação e integração entre as } \\
\text { fases de produção da matéria-prima e as fases industrial e distributiva. } \\
\text { Proveniente do termo francês Filière (fileira), que remete a uma seqüência de } \\
\text { atividades empresariais que conduzem a uma sucessiva transformação de } \\
\text { bens, do estado bruto ao acabado ou designadas ao consumo. }\end{array}$ \\
\hline $\begin{array}{c}\text { Masquiett } \\
\text { o, } \\
\text { Sacomano } \\
\text { Neto e } \\
\text { Giuliani } \\
\text { (2010) }\end{array}$ & $\begin{array}{l}\text { Pode-se definir a cadeia produtiva como um conjunto de etapas que, de fato, } \\
\text { agregam valor em um processo produtivo. Neste sentido, para poder } \\
\text { visualizar globalmente uma cadeia produtiva, num primeiro momento se faz } \\
\text { necessário conhecer o ciclo de vida do produto em questão e, em seguida, é } \\
\text { preciso analisar a interação entre os seus participantes. }\end{array}$ \\
\hline
\end{tabular}

Fonte: Lastres e Cassiolato (2005); Souza e Pereira (2006); Batalha (2007); Severino e Eid (2007); Infante e Santos (2007); Osório (2007); Rech (2008); Masquietto, Sacomano Neto e Giuliani (2010)

De acordo com Lastres e Cassiolato (2005); Souza e Pereira (2006); Batalha (2007); Severino e Eid (2007); Infante e Santos (2007); Osório (2007); Rech (2008); Masquietto, Sacomano Neto e Giuliani (2010), visualiza-se que o entendimento Revista Produção Online, Florianópolis, SC, v.12, n. 3, p. 827-854, jul./set. 2012. 
sobre Cadeia Produtiva segue a mesma linha de raciocínio, logo pode-se convergir para a seguinte definição: consiste em um conjunto de operações sucessivas responsáveis por transformações dissociáveis desde a obtenção de matéria-prima até a comercialização dos respectivos produtos finais. Cada membro da cadeia é responsável pela realização de diferentes etapas do processo e podem estar localizados em regiões ou localidades distintas.

\subsection{Condomínio Industrial}

No Quadro 7 apresentam-se cinco (05) definições para Condomínio Industrial.

Entre as definições para Condomínio Industrial, nota-se que há certo grau de complementaridade entre os autores, porém, há uma pequena discordância no que tange a localização dos fornecedores. Segundo Pires e Sacomano Neto (2010), eles instalam-se dentro dos "muros" que delimitam a planta da montadora, Franco (2009); Pires e Marques (2009); Venanzi e Silva (2010) por sua vez afirmam que os mesmos encontram-se instalados ao redor, nas proximidades da montadora.

Levando-se em consideração este fator conflituoso, pode-se sugerir a seguinte definição para Condomínio Industrial: consiste em uma infraestrutura que se configura quando empresas montadoras reúnem, ao redor de sua fábrica, seus principais fornecedores diretos, chamados de sistemistas, os quais abastecem a montadora diretamente ao lado da linha de montagem, mas não participam da linha de montagem final do produto, a qual permanece a cargo da montadora.

No Condomínio Industrial é a empresa montadora que decide quem irá participar como empresa fornecedora; que suprimentos serão fornecidos; onde os fornecedores se localizarão; e como deverão ser realizadas as entregas com relação à freqüência, às especificações técnicas e ao preço dos suprimentos. Na maioria dos casos, a montadora não exige necessariamente que os recursos dos sistemistas sejam dedicados exclusivamente ao seu abastecimento, o que garante aos mesmos maior flexibilidade e menor dependência da montadora do que no Consórcio Modular (PIRES; SACOMANO NETO, 2010). 
Quadro 7 - Definições para Condomínio Industrial

\begin{tabular}{|c|l|}
\hline Autoria & \multicolumn{1}{c|}{ Definições } \\
\hline Franco & O condomínio industrial é configurado quando as montadoras reúnem, ao \\
& redor de sua fábrica, seus principais fornecedores, definindo partes ou \\
& módulos a serem produzidos e estipulando que lhe construam plantas \\
& dedicadas. Atuando no mesmo sítio, e muitas vezes na mesma edificação, \\
& montadoras e fornecedores constroem relações de dependência mútua, \\
& numa espécie de rede hierarquizada, na qual a montadora detém o \\
domínio da estratégia de desenvolvimento e operação da planta.
\end{tabular}

Fonte: Franco (2009); Pires e Marques (2009); Guarnieri, Hatakeyama e Resende (2009); Pires e Sacomano Neto (2010); Venanzi e Silva (2010)

\subsection{Consórcio Modular}

Por fim, no Quadro 8 são apresentadas cinco (05) definições para Consórcio Modular. 
Quadro 8 - Definições para Consórcio Modular

\begin{tabular}{|c|c|}
\hline Autoria & Definições \\
\hline $\begin{array}{c}\text { Kubo } \\
\text { (2007) }\end{array}$ & $\begin{array}{l}\text { O conceito de Consórcio Modular tem como base a idéia de fornecedores } \\
\text { como parceiros, e visa minimizar os custos fixos e variáveis. Esses } \\
\text { parceiros são responsáveis por parte do investimento da planta, } \\
\text { compartilhando os riscos do empreendimento. Tanto as operações de } \\
\text { montagem, quanto as instalações também, são de responsabilidade do } \\
\text { parceiro, que define aspectos como layout do processo de seu módulo, } \\
\text { sua rede de fornecedores e logística. }\end{array}$ \\
\hline $\begin{array}{l}\text { Sacomano } \\
\text { Neto e Truzzi } \\
(2009)\end{array}$ & $\begin{array}{l}\text { No consórcio modular, o produto é montado integralmente pelos } \\
\text { fornecedores modulistas, que estão instalados dentro da planta da } \\
\text { montadora. A montadora somente controla a qualidade dos produtos finais } \\
\text { montados pelos fornecedores. Ela também realiza compras de } \\
\text { componentes para os fornecedores, os quais são responsáveis por } \\
\text { controlar a logística e a qualidade dos fornecedores de segundo nível, } \\
\text { aqueles que entregam componentes para os fornecedores modulistas. }\end{array}$ \\
\hline $\begin{array}{l}\text { Pires e } \\
\text { Marques } \\
(2009)\end{array}$ & $\begin{array}{l}\text { No consórcio modular, a empresa coloca na mão de seu fornecedor a } \\
\text { responsabilidade da linha de produção, ficando responsável somente pela } \\
\text { inspeção final do produto e pela auditoria. Este conceito estabelecido } \\
\text { pressupõe a transferência para um pequeno número de fornecedores, de } \\
\text { primeira linha, da maior parte das operações de montagem, que } \\
\text { anteriormente estavam a cargo da montadora. Assim, a responsabilidade } \\
\text { de continuidade da linha de produção está integralmente nas mãos dos } \\
\text { fornecedores. Com isso, todo processo decisório ocorrido dentro da } \\
\text { empresa tem a participação dos mesmos. }\end{array}$ \\
\hline $\begin{array}{l}\text { Franco } \\
\text { (2009) }\end{array}$ & $\begin{array}{l}\text { O consórcio modular pressupõe uma terceirização radical, na qual os } \\
\text { fornecedores são responsáveis pela montagem e por garantir os módulos } \\
\text { de montagem, enquanto a montadora, que dá a "marca", faz a supervisão } \\
\text { e o teste dos produtos produzidos. }\end{array}$ \\
\hline $\begin{array}{l}\text { Pires e } \\
\text { Sacomano } \\
\text { Neto } \\
(2010)\end{array}$ & $\begin{array}{l}\text { O consórcio modular pode ser considerado um caso radical de } \\
\text { terceirização em que os fornecedores-chave, chamados de sistemistas, } \\
\text { assumem a montagem prévia do módulo sob sua responsabilidade e sua } \\
\text { posterior montagem diretamente na linha de montagem final da } \\
\text { montadora, os investimentos em equipamentos e ferramentas e a gestão } \\
\text { (mesmo que parcial) da cadeia de suprimentos do módulo. Por sua vez, a } \\
\text { montadora providencia a planta e a linha de montagem final, executa a } \\
\text { coordenação desta e o teste final dos produtos. }\end{array}$ \\
\hline
\end{tabular}

Fonte: Kubo (2007); Sacomano Neto e Truzzi (2009); Pires e Marques (2009); Franco (2009); Pires e Sacomano Neto (2010)

Vale destacar o que vem a ser a modularidade ou modularização: uma maneira de construir um produto ou processo complexo através de subsistemas menores, que podem ser projetados independentemente e, ainda assim, operarem juntos como um todo (BALDWIN; CLARK, 2000). A modularização é um conceito no projeto do produto, cujo produto final é construído de um número de módulos do produto. Os módulos são montados para configurar um grande número de variações do produto final (MIKKOLA, 2006). 
Segundo Kubo (2007), a divisão do produto em módulos foi idealizada pela montadora de veículos Volkswagen, com intuito de viabilizar a entrega de grande parte da produção à responsabilidade de uma empresa parceira (modulista), e ao mesmo tempo racionalizar a produção. Ao final do processo, a empresa formou 7 módulos: chassis, eixos e suspensão, montagem de rodas, motor, estamparia e armação de cabine, pintura e montagem interna.

Diante das definições para Consórcio Modular de Kubo (2007); Sacomano Neto e Truzzi (2009); Pires e Marques (2009); Franco (2009); Pires e Sacomano Neto (2010) pode-se sugerir a seguinte definição para Consórcio Modular: consiste em um caso de terceirização radical entre uma montadora e um pequeno número de fornecedores diretos, chamados de modulistas, que ficam instalados dentro da planta da própria montadora. Neste tipo de Arranjo os fornecedores são responsáveis pela montagem prévia do módulo e pela montagem final na linha de produção da montadora. Os investimentos em equipamentos e ferramentas, e o gerenciamento parcial do módulo também ficam a cargo dos modulistas, já a montadora, que dá a marca, providencia a planta e a linha de montagem final, executa a coordenação da mesma, e a inspeção final dos produtos. Logo, percebese um aumento da responsabilidade atribuída aos fornecedores, e a necessidade de relações de parcerias mais fortes.

\section{MÉTODOS DE PESQUISA}

Nesta seção serão delineados os aspectos metodológicos que serviram de suporte e diretriz na condução do presente estudo. Quanto a sua natureza, trata-se de uma pesquisa básica, descritiva e bibliográfica, na qual foram coletadas em livros, artigos, monografias, dissertações, teses, etc. várias definições sobre cada tipo de Arranjo Empresarial em estudo.

Com intuito de expor definições que vem sendo utilizadas atualmente nas diversas fontes de pesquisa, limitou-se o estudo àquelas bibliografias publicadas ou apresentadas entre os anos de 2005 e 2011.

Os Arranjos Empresariais que tiveram suas definições coletadas e analisadas foram: Arranjo Produtivo Local (APL), Clusters, Redes de Empresas, Cooperativas, Cadeia Produtiva ou Filière, Cadeia de Suprimentos ou Supply Chain, Condomínio 
Industrial e Consórcio Modular. A escolha destes tipos específicos de Arranjos segue a classificação proposta por Brito e Leite (2008); Leite, Brito e Oliveira (2009).

A execução da pesquisa consistiu em três etapas:

i. Elaboração de 08 Quadros com definições sobre cada um dos principais tipos de Arranjos Empresariais, autores e ano de publicação e/ou apresentação;

ii. Análise das definições coletadas e formulação de definições gerais a partir da interpretação das principais características apontadas por cada autor;

iii. Discussão das diferenças perceptíveis entre os tipos de Arranjos que mais se assemelham em suas definições, de acordo com o que foi diagnosticado na etapa (ii). Nesta etapa buscou-se analisar as diferenças a partir da formação de conjuntos dos tipos de Arranjos mais semelhantes, como: conjunto A - Arranjo Produtivo Local, Cluster, Rede de Empresas e Cooperativas; conjunto B - Cadeia de Suprimentos e Cadeia Produtiva; e conjunto C - Condomínio Industrial e Consórcio Modular.

Por fim, a partir das definições analisadas e das diferenças discutidas, foi estruturado o Quadro 9, com as características pontuais de cada Arranjo, as quais buscam a possibilidade de diferenciá-los no campo teórico. No eixo horizontal foram dispostos os tipos de Arranjos e no eixo vertical as características dominantes. Em cada uma das características típicas de um Arranjo específico foi marcado um "X" na célula de intersecção correspondente entre o Arranjo e a característica.

\section{DISCUSSÃO SOBRE AS DIFERENÇAS EXISTENTES ENTRE OS ARRANJOS EMPRESARIAIS ESTUDADOS}

A partir das definições gerais sugeridas, foram diagnosticados aqueles tipos de Arranjos Empresariais que mais se assemelham. Assim, nesta seção serão apresentadas algumas das diferenças mais perceptíveis entre eles. Para facilitar a compreensão, a discussão das diferenças foi dividida em três partes que estão diretamente vinculadas ao conjunto daqueles tipos de Arranjos semelhantes em suas definições: 4.1 Diferenças entre Arranjo Produtivo Local, Clusters, Redes de Empresas e Cooperativas; 4.2 Diferenças entre Cadeia de Suprimentos e Cadeia Produtiva; e 4.3 Diferenças entre Condomínio Industrial e Consórcio Modular. 


\subsection{Diferenças entre APL, Clusters, Redes de Empresas e Cooperativas}

Dentre os tipos de Arranjos em análise, Clusters e APL são aqueles definidos com conceitos praticamente iguais, na verdade o principal aspecto que os diferencia diante das definições abordadas, é que o APL trata-se de um tipo específico de Cluster, que abrange Pequenas e Médias Empresas (TEIXEIRA, NASCIMENTO FILHO, 2007; GALDÁMEZ, CARPINETTI, GEROLAMO, 2009).

Em relação às Redes de Empresas, um fator que as diferencia é a não obrigação da proximidade espacial de seus integrantes (LASTRES; CASSIOLATO, 2005), ou seja, as organizações encontram-se geograficamente dispersas (VERNADAT, 2010), diferentemente do APL e Clusters em que a concentração geográfica é uma de suas principais características. Nas Redes não há a presença de outros atores além das entidades empresariais independentes, não há como no Cluster e no APL um apoio de sistemas de valores incluindo outros tipos de organizações como universidades, instituições financeiras, etc. Além disso, nas Redes existe a possibilidade de formulação de acordos formais (NAKANO, 2005; RING, PEREDO, CHRISMAN, 2010).

No tocante às Cooperativas comparando-as aos Arranjos supracitados conclui-se que elas apresentam peculiaridades em sua constituição legal, com a adoção de princípios e doutrinas que exercem significativos reflexos na sua estruturação e governança, delegação e exercício de poder e na forma como ocorre o processo decisório (BARREIROS; PROTIL, 2005). Consiste em uma organização em que os seus membros concordam entre si para criar uma empresa e operá-la em conjunto como parte integrante de suas empresas individuais (FENG; HENDRIKSE, 2007), o que não ocorre nos casos de Cluster, APL e Redes de Empresas.

\subsection{Diferenças entre Cadeia de Suprimentos e Cadeia Produtiva}

Cadeia de Suprimentos e Cadeia Produtiva são conceitos interligados, sendo por vezes considerados sinônimos. No entanto, há algumas diferenças relevantes entre estes Arranjos, principalmente em relação à sua composição.

Para Faria e Costa (2005); Ballou (2006); Christopher (2007); Menezes, Guimarães e Sellito (2008); Thakkar, Kanda e Deshmukh (2008); Barros e Alencar 
(2009); Wang et al. (2009); e Mo, Harrison e Barton (2011), a Cadeia de Suprimentos é conceituada como um conjunto ou rede de organizações que trabalham juntas a fim de, necessariamente, agregar valor ao produto e/ou serviço. Lastres e Cassiolato (2005); Souza e Pereira (2006); Batalha (2007); Severino e Eid (2007); Infante e Santos (2007); Osório (2007); Rech (2008); e Masquietto, Sacomano Neto e Giuliani (2010) afirmam que Cadeia Produtiva seria um conjunto sucessivo de etapas ou operações ou atividades de transformação da matéria-prima em produto acabado, em que, segundo Lastres e Cassiolato (2005), cada membro é responsável pela realização de diferentes etapas do processo.

Constata-se que o primeiro Arranjo é composto por um maior contingente de participantes que o segundo, já que na Cadeia de Suprimentos além das operações voltadas à produção, distribuição e comercialização há, ainda, as operações logísticas (MO; HARRISON; BARTON, 2011). Ou seja, por contemplar mais atividades que a Cadeia Produtiva, a Cadeia de Suprimentos mostra-se como um Arranjo com um maior número de atores envolvidos, fazendo com que emirja outra característica importante em sua definição que é o fluxo de informações de forma mais intensa. É importante frisar, ainda, que os termos não são excludentes, uma Cadeia Produtiva possui sua Cadeia de Suprimentos e vice-versa.

\subsection{Diferenças entre Condomínio Industrial e Consórcio Modular}

O Consórcio Modular e o Condomínio Industrial apresentam-se como tipos de Arranjos de natureza particular, necessitam da presença dos fornecedores localizados próximos às empresas montadoras, além de representarem casos de terceirização. Logo, apresentam conceitos semelhantes, porém é possível destacar algumas características significativas que tornam possível a sua diferenciação:

a) no Condomínio Industrial os fornecedores encontram-se nas proximidades da empresa montadora (FRANCO, 2009; PIRES, MARQUES, 2009; VENANZI, SILVA, 2010), já no Consórcio Modular os mesmos encontram-se instalados dentro da própria planta da montadora (SACOMANO NETO; TRUZZI, 2009);

b) no Condomínio Industrial, a montadora não exige necessariamente que os recursos dos modulistas sejam dedicados exclusivamente ao seu abastecimento, $\mathrm{o}$ 
que garante aos mesmos maior flexibilidade e menor dependência da montadora de que no caso do Consórcio Modular (PIRES; SACOMANO NETO, 2010);

c) no Consórcio Modular os fornecedores são responsáveis, além do fornecimento de insumos, pela montagem final dos produtos (KUBO, 2007; SACOMANO NETO, TRUZZI, 2009; PIRES, MARQUES, 2009; FRANCO, 2009; PIRES, SACOMANO NETO, 2010), no Condomínio Industrial a montagem final permanece sob responsabilidade da montadora (GUARNIERI, HATAKEYAMA, RESENDE, 2009; PIRES, SACOMANO NETO, 2010).

d) a aplicação do Consórcio Modular é um pouco mais radical que o Condomínio Industrial, tanto no que se refere à localização dos fornecedores, como à sua responsabilidade junto às montadoras, o que é corroborado por Guarnieri, Hatakeyama e Resende (2009); Franco (2009); Pires e Sacomano Neto (2010).

No estudo não se entrou no mérito da discussão da diferença do que seja um sistema e um módulo, optou-se por utilizar o temo genérico sistema/módulo, seguindo as definições dos autores analisados.

\section{CONSIDERAÇÕES FINAIS}

É notável a dificuldade que existe na literatura em formar conceitos uniformes para os diversos tipos de Arranjos Empresariais, porém a partir da obtenção de algumas definições foi possível elaborar definições gerais e uniformes, e com isso contribuir para a formação de diferenças significativas entre os mesmos.

Após analisar as definições de diversos autores constatou-se que APL e Cluster são os que mais apresentam semelhanças. Da forma como estes Arranjos vêm sendo conceituados leva-se a um falso entendimento de que os dois seriam um tipo único, situação esta que dificultou a formação de uma diferença mais forte entre os mesmos, e concentrada apenas no porte das empresas que os compõe.

No tocante à Rede de Empresas e Cooperativas, as definições coletadas subsidiaram a formação de diferenças importantes já que estes tipos de Arranjos apresentam características distintivas em relação à Cluster e APL, principalmente em relação à sua composição e proximidade dos membros no que se refere à Rede de Empresas, e constituição legal no caso das Cooperativas. 
Cadeia de Suprimentos e Cadeia Produtiva diferenciam-se dos primeiros Arranjos analisados e dos subseqüentes por tratarem-se de formatos em que cada um dos seus membros é responsável por uma atividade específica dentro da cadeia desde a obtenção da matéria-prima até o cliente final. Agregando valor no caso da Cadeia de Suprimentos, ou desenvolvendo um produto a partir de operações sucessivas de transformações dissociáveis no caso de uma Cadeia Produtiva.

Quadro 9 - Arranjos Empresariais e suas características

\begin{tabular}{|c|c|c|c|c|c|c|c|c|}
\hline $\begin{array}{ll}\text { Características } & \text { Tipos de Arranjos }\end{array}$ & APL & CL & RE & co & cs & CP & CM & Cl \\
\hline Agregação de valor ao produto & & & & & $\bar{X}$ & & & \\
\hline Concentração geográfica de empresas & $\mathrm{X}$ & " $\mathrm{x}$ & & & & & & \\
\hline Concentração setorial de empresas & $\mathrm{X}$ & $\mathrm{x}$ & & & & & & \\
\hline Criação de uma empresa gerida coletivamente & & & & 'X & & & & \\
\hline $\begin{array}{l}\text { Divisão democrática e ajuda mútua entre } \\
\text { membros }\end{array}$ & & & & $\mathbf{X}$ & & & & \\
\hline $\begin{array}{l}\text { Empresa montadora que decide quem irá } \\
\text { participar como empresa fornecedora }\end{array}$ & & & & & & & & $\mathrm{X}$ \\
\hline Empresas de pequeno e médio porte & $\mathrm{x}$ & & & & & & & \\
\hline $\begin{array}{l}\text { Estende-se da obtenção da matéria-prima ao } \\
\text { consumidor final }\end{array}$ & & & & & $\mathrm{X}$ & $\mathrm{X}$ & & \\
\hline Existência ou não de acordos/contratos formais & & & $\mathrm{X}$ & & & & & \\
\hline Formado por empresas e instituições de apoio & $\mathrm{x}$ & $\mathrm{x}$ & & & & & & \\
\hline $\begin{array}{l}\text { Fornecedores instalados dentro da planta da } \\
\text { empresa montadora }\end{array}$ & & & & & & & $\mathrm{X}$ & \\
\hline Fornecedores instalados próximos à montadora & & & & & & & & $\mathrm{X}$ \\
\hline $\begin{array}{l}\text { Fornecedores responsáveis pela montagem } \\
\text { final }\end{array}$ & & & & & & & $\mathrm{X}$ & \\
\hline Forte integração de informações & & & & & X & & & \\
\hline Introdução de inovações & $\mathrm{x}$ & $\mathrm{x}$ & & & & & & \\
\hline Mix de competição e cooperação & & X & & & & & & \\
\hline $\begin{array}{l}\text { Não há a presença de outros atores, além das } \\
\text { entidades empresariais independentes }\end{array}$ & & & $\mathrm{x}$ & & & & & \\
\hline $\begin{array}{l}\text { Não implica necessariamente na proximidade } \\
\text { espacial de seus integrantes }\end{array}$ & & & $\mathrm{x}$ & & & & & \\
\hline Operações logísticas inseridas & & & & & $\mathrm{x}$ & & & \\
\hline Operações produtivas sucessivas e dissociáveis & & & & & & X & & \\
\hline Organização de pessoas & & & & $\mathrm{X}$ & & & & \\
\hline Peculiaridades na constituição legal & & & & X & & & & \\
\hline $\begin{array}{l}\text { Recursos dos fornecedores são dedicados } \\
\text { exclusivamente ao abastecimento da montadora }\end{array}$ & & & & & & & $X$ & \\
\hline $\begin{array}{l}\text { Todos os membros realizam etapas do } \\
\text { processo }\end{array}$ & & & & & & $\mathbf{X}$ & & \\
\hline
\end{tabular}

Fonte: Autoria própria

Revista Produção Online, Florianópolis, SC, v.12, n. 3, p. 827-854, jul./set. 2012. 
Em relação a Condomínio Industrial e Consórcio Modular, em virtude de suas naturezas, foi possível diferenciá-los com mais facilidade dos demais tipos de Arranjos, visto que o modo como eles encontram-se dispostos territorialmente os diferem. A existência de uma empresa montadora com seus fornecedores diretos localizados próximo ou na própria planta constitui-se em um diferencial não comum aos outros Arranjos.

Assim, a partir das definições analisadas, das definições gerais sugeridas, e das diferenças discutidas, no Quadro 9 apresenta-se uma matriz das características pontuais que possibilitam diferenciar teoricamente cada um dos tipos de Arranjos estudados: Arranjo Produtivo Local (APL); Cluster (CL); Rede de Empresas (RE); Cooperativas (CO); Cadeia de Suprimentos (CS); Cadeia Produtiva (CP); Consórcio Modular (CM); Condomínio Industrial (Cl).

Este estudo buscou, com a apresentação de definições atuais e diferenças significativas entre os principais tipos de Arranjos Empresariais discutidos na literatura, fornecer informações relevantes para subsidiar pesquisas futuras sobre 0 tema, realização de mapeamento e caracterização de Arranjos, diagnósticos, definição de modelos de gerenciamento, entre outros.

\section{REFERÊNCIAS}

ABREU, B. S.; BARACUHY NETO, G. M.; ARAÚJO, P. S.; BEZERRA, P. T. da C.; FERNANDES NETO, S. Cooperativismo como alternativa para o desenvolvimento regional - o exemplo da COAPECAL. Revista de Geografia. Recife, v. 25, n. 3, set./dez. 2008.

ALBUQUERQUE, F. Desenvolvimento econômico local: caminhos e desafios para a construção de uma nova agenda política. Rio de Janeiro: BNDES, 2001.

AMATO NETO, João. Redes dinâmicas de cooperação e organizações virtuais. In: . (Org.). Redes entre organizações: domínio do conhecimento e da eficácia operacional. São Paulo: Atlas, 2005.

BALDWIN, C. Y.; CLARK, K. B. Design rules: the power of modularity. Cambridge: MIT, 2000.

BALLOU, R. H. Gerenciamento da cadeia de suprimentos/logística empresarial. 5. ed. Porto Alegre: Bookman, 2006.

BARBOSA, F. A.; SACOMANO. J. B.; PORTO, A. J. V. Metodologia de análise para redes interorganizacionais: competitividade e tecnologia. Gest. Prod., São Carlos, v. 14, n. 2, p. 411-423, maio/ago. 2007.

Revista Produção Online, Florianópolis, SC, v.12, n. 3, p. 827-854, jul./set. 2012. 
BARREIROS, R. F.; PROTIL, R. M. Variáveis associadas ao processo decisório em nível estratégico nas cooperativas agropecuárias do paraná. In: ENCONTRO NACIONAL DE ENGENHARIA DE PRODUÇÃO (ENEGEP), 25., 2005. Anais... Porto Alegre, RS, 2005.

BARROS, R. A. A relação dos índices de desenvolvimento sustentável municipal com a competitividade agroindustrial: o caso do arranjo produtivo local de cachaça em Areia - PB. 162 p. Dissertação (Mestrado em Engenharia de Produção) - Programa de Pós-Graduação em Engenharia de Produção, Universidade Federal da Paraíba, João Pessoa, PB, 2010.

BARROS, F. C.; ALENCAR, L. H. Análise da cadeia de suprimentos de um empreendimento habitacional de interesse social. In: ENCONTRO NACIONAL DE ENGENHARIA DE PRODUÇÃO - ENEGEP, 29.,2009. Anais.... Salvador, BA, 2009.

BATALHA, M. O. Gestão agroindustrial. 2. ed. São Paulo: Atlas, 2007.

BRITO, A. M.; LEITE, M. S. A. Discussão sobre as características dos diferentes Arranjos Empresariais. In: ENCONTRO NACIONAL DE ENGENHARIA DE PRODUÇÃO - ENEGEP, 28., 2008. Anais... Rio de Janeiro - RJ, 2008.

BRITTO, J.; STALLIVIERI, F. Inovação, cooperação e aprendizado no setor de software no Brasil: análise exploratória baseada no conceito de Arranjos Produtivos Locais (APLs). Economia e Sociedade, Campinas - SP, v. 19, n. 2 (39), p. 315 - 358, ago 2010.

BRUNNER, Daniel; VOIGT, Tim. Innovation processes in Cooperative Organizations: Results from a Case Study Research. EMNet, Conference RSM, Erasmus University Rotterdam, Netherlands, 2007.

CABETE, N. P. F.; DACOL, S. Identificação das características dos Arranjos Produtivos Locais. In: ENCONTRO NACIONAL DE ENGENHARIA DE PRODUÇÃO - ENEGEP, 28., 2008. Anais... Rio de Janeiro - RJ, 2008.

CAVALCANTE, A. T. M. Financiamento e desenvolvimento local: um estudo sobre Arranjos Produtivos. 162 f. Dissertação (Mestrado em Economia) - Centro de Desenvolvimento e Planejamento Regional de Minas Gerais, Universidade Federal de Minas Gerais, Belo Horizonte - MG, 2006.

CHIARONI, Davide; CHIESA, Vittorio. Forms of creation of industrial clusters in biotechnology. Technovation, v. 26, p. 1064-1076,2006.

CHRISTOPHER, M. Logística e gerenciamento da cadeia de suprimentos: criando redes que agregam valor. 2. ed. São Paulo: Thomson Learning, 2007.

CORTRIGHT, J. Making sense of clusters: regional competitiveness and economic development. The Brookings Institution Metropolitan Policy Program, 2006. 
CROCCO, M. A.; GALINARI, R.; SANTOS, F.; LEMOS, M. B.; SIMÕES, R. Metodologia de Identificação de arranjos produtivos locais potenciais. Texto para Discussão 212 - Belo Horizonte: UFMG/CEDEPLAR, 2003.

FARIA, A. C.; COSTA, M. F. G. Gestão de custos logísticos. São Paulo: Atlas, 2005.

FENG, Li; HENDRIKSE, George. On the nature of a cooperative: a system of attributes perspective. ERIM Report Series Research in Management, Netherlands, 2007.

FRANCO, Angela. Em tempos globais, um "novo" local: a Ford na Bahia. Caderno CRH. Salvador, v. 22, n. 56, p. 359-380, 2009.

GALDÁMEZ, E. V. C.; CARPINETTI, L. C. R.; GEROLAMO, M. C. Proposta de um sistema de avaliação do desempenho para arranjos produtivos locais. Gest. Prod. São Carlos, v. 16, n. 1, p. 133-151, jan./mar. 2009.

GALETI, Rinaldo Aparecido. Aglomerações produtivas ou clusters industriais na indústria de transformação da região Sul. Perspec. Contemp., Campo Mourão, v. 2, n. 2, p. 44-78, jul./dez. 2007.

GUARNIERI, P.; HATAKEYAMA, K.; RESENDE, L. M. Estudo de caso de um condomínio industrial na indústria automobilística: caso GM Gravataí. Rev.

Produção Online, v. 9, n. 1, 2009.

GUERRINI, F. M. Taxonomia de formas organizacionais de produção a partir do recorte analítico de redes de empresas. In: FUSCO, J. P. A. (Org.). Redes produtivas e cadeias de fornecimento. São Paulo: Arte \& Ciência, 2005.

HUMAN, S. E.; PROVAN, K. G. Na emergent theory of structure and autcomes in small-firm strategic manufacturing networks. Academy of Management Journal, v.40, n.2, p.368-403, 1997.

INFANTE, M.; SANTOS, M. A. B. A organização do abastecimento do hospital público a partir da cadeia produtiva: uma abordagem logística para a área de saúde. Ciência \& saúde coletiva, v.12, n.4, p. 945-954, 2007.

JIA, Wei; LIU, Li-ran; XIE, Xue-mei. Diffusion of technical innovation based on industry-university-institute cooperation in industrial clusters. The Journal of China Universities of Posts and Telecommunications, v.17, p 45-50, 2010.

JORDE, T. M.; TEECE, D. J. Competition and cooperation: striking the right balance. Business \& Public Policy, Spring, 1989.

KELLER, P. F. Clusters, distritos industriais e cooperação interfirmas: uma revisão da literatura. Revista Economia \& Gestão. Minas Gerais, v. 8, n. 16, p. 30-47, 2008. 
KUBO, Pablo Yugo Y. Consórcio modular: uma análise da implantação do modelo estratégico para obtenção de vantagens competitivas. 79 p. Dissertação (Mestrado em Gestão Estratégica de Negócios) - Instituto de Ciências Humanas e Sociais, Universidade Federal Rural do Rio de Janeiro, Rio de Janeiro - RJ, 2007.

LASTRES, H. M. M.; CASSIOLATO, J. E. Mobilizando conhecimentos para desenvolver arranjos e sistemas produtivos e inovativos locais de micro e pequenas empresas no brasil. Glossário de Arranjos e Sistemas Produtivos e Inovativos Locais. Projeto, Apoio: SEBRAE, 8. Revisão, 2005.

LEITE, M. S. A.; BRITO, A. M.; OLIVEIRA, J. B. Proposta de um framework com traços distintivos como base para a implantação de sistemas de gestão de custos: aplicação teórica nos formatos organizacionais estabelecidos na mesoregião do semiárido. GEPROS - Gestão da Produção, Operações e Sistemas v.4, n. 1, jan./mar. 2009, p. 117-132.

MACHADO, B. A.; MORAES, G. G.; CASTRO, R. de.; MANFRINATO, J. W. de S.; WIENS, I. A importância social e econômica da implementação de cooperativas de materiais recicláveis. In: ENCONTRO NACIONAL DE ENGENHARIA DE PRODUÇÃO - ENEGEP, 26., 2006. Anais... Fortaleza - CE, 2006.

MALUF, Rosemma B. Programa de desenvolvimento do APL de confecções rua do Uruguai e entorno. Programa de Requalificação da Península de Itapagipe, Salvador - BA, 2005.

MASQUIETTO, C. D.; SACOMANO NETO, M.; GIULIANI, A. C. Identificação de arranjos produtivos locais: o caso do arranjo produtivo local de Piracicaba. Gestão \& Regionalidade, v. 26, n. 77, maio/ago. 2010.

MENEZES, T. M.; GUIMARÃES, M. G.; SELLITTO, M. A. Medição de indicadores logísticos em duas operações de montagem abastecidas por cadeias de suprimentos. Revista Produção Online, v.8, n.1, mar. 2008.

MIKKOLA, J. H. Product development \& management association capturing the degree of modularity embedded in product architectures. J Prod Innov Manag, v. 23, p. 128-146, 2006.

MO, Yin; HARRISON, T. P.; BARTON, R. R. Solving stochastic programming models in supply chain design using sampling heuristics. IMA Journal of Management Mathematics, v.22, p. 65-77, 2011.

MORI, C. de; BATALHA, M. O.; ALVES FILHO, A. G. Abordagens espaço-relacional de organização da produção em estudos de atividades de produção agroindustrial no Brasil. Revista Brasileira de Gestão e Desenvolvimento Regional. Taubaté, v. 5, n. 3, p. 94 - 115, set./dez. 2009, - SP.

MOZZATO, A. R. Relações interorganizacionais: Cooperação e competição como vantagem competitiva para o arranjo produtivo de gemas e pedras preciosas de 
soledade. In: ENCONTRO DE ESTUDOS ORGANIZACIONAIS DA ANPAD,6,. 2010. Anais... Florianópolis - SC, 2010.

NAKANO, D. N. Fluxos de conhecimentos em redes interorganizacionais: conceitos e fatores de influência. In: AMATO NETO, João (Org.). Redes entre organizações: domínio do conhecimento e da eficiência operacional. São Paulo: Atlas, 2005.

NOVKOVIC, Sonja. Defining the co-operative difference. The Journal of SocioEconomics, v.37, p. 2168-2177, 2008.

OLIVEIRA, Verônica M. de.; CÂNDIDO, Gesinaldo, A. Consolidação de redes interempresariais: um estudo exploratório no setor varejista de supermercados. In: Encontro Nacional de Engenharia de Produção - ENEGEP, 29., 2009. Anais... Salvador - BA, 2009.

OSÓRIO, Estela Gonçalves. Implantação de papel e celulose: Estudo de caso da implantação da VCP Florestal no extremo Sul do Rio Grande do Sul. 58 p. Monografia (Graduação em Ciências Econômicas) - Departamento de Ciências Econômicas, Universidade Federal de Santa Catarina, Florianópolis - SC, 2007.

PIRES, L. M.; MARQUES, M. J. Condomínio industrial e consorcio modular gerenciamento de alianças logísticas estratégicas na busca de fatores competitivos. 56 p. Monografia (Graduação em Engenharia de Produção) Faculdade Pitágoras, Ipatinga -MG, 2009.

PIRES, S. R. I.; SACOMANO NETO, M. Características estruturais, relacionais e gerenciais na cadeia de suprimentos de um condomínio industrial na indústria automobilística. Revista Produção, v. 20, n. 2, p. 172-185, abr./jun. 2010.

RECH, S. R. Cadeia produtiva da moda: um modelo conceitual de análise de competitividade no elo confecção. DAPesquisa Revista de investigação em Artes, v. 1 , n. 3, 2008.

RING, J. K.; PEREDO, A. M.; CHRISMAN, J. J. Business networks and economic development in rural communities in the united states. Entrepreneurship Theory \& Practice Journal, 2010.

SACOMANO NETO, M.; TRUZZI, Oswaldo M. S. Posicionamento estrutural e relacional em redes de empresas: uma análise do consórcio modular da indústria automobilística. Gest. e Prod., São Carlos, v. 16, n. 4, p. 598-611, out./dez. 2009.

SEVERINO, M. R.; EID, F. Integração de cadeias produtivas em empreendimentos de economia solidária: uma adaptação do conceito da empresa capitalista. In: Encontro Nacional de Engenharia da Produção - ENEGEP, 27., 2007. Anais...Foz do Iguaçu - PR, 2007.

SCHMITZ, H.; NADVI, K. Clustering and industrialization: introduction. World Development. Oxford, v.27, n.9, p.1503-1514, 1999. 
SOUZA, J. P. de.; PEREIRA, L. B. Elementos básicos para estudo de cadeias produtivas: tratamento teórico-analítico. In: SIMPÓSIO DE ENGENHARIA DE PRODUÇÃO - SIMPEP, 13., 2006. Anais... Bauru - SP, 2006.

SUZIGAN, W (Coord.). Identificação, mapeamento e caracterização estrutural de arranjos produtivos locais no Brasil. Instituto de Pesquisa Econômica Aplicada IPEA, Diretoria de Estudos Setoriais - DISET, out. 2006.

TEIXEIRA, R. B.; NASCIMENTO FILHO, R. S. A consolidação dos arranjos produtivos locais como mecanismos de desenvolvimento sustentável e inclusão social. In: Encontro Nacional de Engenharia de Produção - ENEGEP, 27.,2007. Anais... Foz do Iguaçu -PR, 2007.

THAKKAR, J.; KANDA, A.; DESHMUKH, S. G. Evaluation of buyer-supplier relationships using an integrated mathematical approach of interpretive structural modeling (ism) and graph theoretic matrix the case study of indian automotive SMES. Journal of Manufacturing Technology Management, v. 19, n. 1, p. 92-124, 2008.

VASCONCELOS, F. C.; GOLDSZMIDT, R. G. B.; FERREIRA, Fernando C. M. Arranjos Produtivos. São Paulo, v. 4, n.3, ago./out. 2005.

VENANZI, D.; SILVA, O. R. Arranjos de condomínio industrial e consórcio modular na indústria automobilística brasileira: uma análise de múltiplos casos. In: SIMPÓsıO DE ADMINISTRAÇÃO DA PRODUÇÃO, LOGÍSTICA E OPERAÇÕES INTERNACIONAIS - SIMPOI. Anais..., 2010.

VERNADAT, François B. Technical, semantic and organizational issues of enterprise interoperability and Networking. Annual Reviews in Control, v. 34, p. 139-144, 2010.

WANG, M.; WANG, H.; VOGEL, D.; KUMAR, K.; CHIU, DKW. Agent-based negotiation and decision making for dynamic supply chain formation. Engineering Applications of Artificial Intelligence, v. 22, n. 7, p. 1046-1055, 2009.

WINCKLER, N. C.; MOLINARI, G. T. Competição, colaboração, cooperação e coopetição: revendo os conceitos em estratégias interorganizacionais. Revista ADMpg Gestão Estratégica, v. 4, n. 1, 2011.

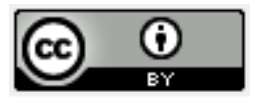

Artigo recebido em 26/04/2011 e aceito para publicação em 29/03/2012. 